\title{
Papers
}

\section{Association between stressful life events and exacerbation in multiple sclerosis: a meta-analysis}

David C Mohr, Stacey L Hart, Laura Julian, Darcy Cox, Daniel Pelletier

\begin{abstract}
Objective To quantify the association between stressful life events and exacerbations of multiple sclerosis.

Data sources PubMed, PsychInfo, and Psychological Abstracts searched for empirical papers from 1965 to February 2003 with terms "stress", "trauma", and "multiple sclerosis".

Review methods Three investigators independently reviewed papers for inclusion/exclusion criteria and extracted the relevant data, including methods, sample statistics, and outcomes.

Results Of 20 studies identified, 14 were included. The meta-analysis showed a significant increase in risk of exacerbation in multiple sclerosis after stressful life events, with a weighted average effect size of $d=0.53(95 \%$ confidence interval 0.40 to 0.65$), \mathrm{P}<0.0001$. The studies were homogenous, $\mathrm{Q}=16.62, \mathrm{P}=0.22, I^{2}=21.8 \%$. Neither sampling nor study methods had any effect on study outcomes. Conclusions There is a consistent association between stressful life events and subsequent exacerbation in multiple sclerosis. However these data do not allow the linking of specific stressors to exacerbations nor should they be used to infer that patients are responsible for their exacerbations. Investigation of the psychological, neuroendocrine, and immune mediators of stressful life events on exacerbation may lead to new behavioural and pharmacological strategies targeting potential links between stress and exacerbation.
\end{abstract}

\section{Introduction}

Multiple sclerosis is a chronic, often disabling disease in which the immune system attacks the myelin sheath of axons of the central nervous system. ${ }^{1}$ Most people with multiple sclerosis have a relapsing form of the disease, characterised in part by exacerbations in which symptoms appear suddenly within 24 hours. These symptoms remit slowly over the course of weeks or months but often can leave some residual impairment. Symptoms vary considerably across patients and can include loss of function or feeling in limbs, loss of bowel or bladder control, sexual dysfunction, debilitating fatigue, blindness due to optic neuritis, double vision, loss of balance, pain, loss of cognitive functioning, and emotional changes.

Numerous triggers of exacerbation have been proposed, including bacterial or viral infections that cause $\mathrm{T}$ cells to "mistake" myelin proteins for these antigens, bacterial "superantigens," physical injury, or stressful life events. ${ }^{2}$ Of these, the role of stressful life events has been by far the most controversial. ${ }^{3}$

The notion that psychological stress might trigger exacerbation dates back more than 100 years to Charcot, who speculated that grief, vexation, and adverse changes in social circumstance were related to the onset. ${ }^{4}$ Most patients with multiple sclerosis believe that stressful events can cause or contribute to their exacerbations. ${ }^{5}$ Over the past decades numerous empirical studies of the question have been published. Goodin et al's qualitative literature review on the effects of stress on clinical exacerbation arrived at an equivocal conclusion. ${ }^{3}$ While the review contained careful discussions of each paper included, it did not include all relevant studies and did not use quantitative meta-analytic techniques. Furthermore, several important studies have been published since this review.

To clarify the present state of empirical research we conducted a systematic review and quantitative meta-analysis to evaluate and quantify the association between stress and clinical exacerbation in multiple sclerosis.

\section{Methods}

\section{Identification of studies}

We searched PubMed, PsychInfo, and Psychological Abstracts from 1965 to February 2003 using the terms "stress", "trauma", and "multiple sclerosis". Potential unpublished data sources were obtained by using the same keywords in a search on the database of computer retrieval of information on scientific projects (National Institutes of Health). This database includes federally funded ongoing projects. On the basis of title and abstract we manually examined English and non-English reference lists of all articles to locate any other referenced journal articles not identified in the preliminary search.

\section{Inclusion criteria}

We included studies if they used standardised diagnosistic criteria for multiple sclerosis (for example, Schumacher ${ }^{6}$ or Poser $^{7}$ ) with a relapsing course equivalent to current classifications of relapsing-remitting or secondary progressive, or both; exacerbation was confirmed by a neurologist; they used standardised or standard checklist methods through interview or questionnaire to measure stressful life events; they used case-control or longitudinal design; and they provided enough information about results to allow us to compute an estimate of effect size (such as means and standard deviations; group percentages, etc). We excluded studies if stress could not be distinguished from psychopathology or "temperament"; stress included only physical trauma (for example, head injury) or a medical condition, as these might be confounded with outcome measurement; there was no clear effect size or test statistic that allowed us to compute an effect size; or the same data were used for two reports. 


\section{Coding of studies}

Three authors (DCM, LJ, SLH) reviewed all eligible studies. They coded studies on design (case-control $v$ longitudinal prospective); outcome (first diagnosed exacerbation $v$ exacerbation in a diagnosed sample); type of patients, included relapsing-remitting multiple sclerosis $v$ secondary-progressive multiple sclerosis (studies before this distinction were presumed to contain both); use of validated $v$ unvalidated measure of stress; use of self report $v$ structured interview assessment of stress; age; proportion of female patients; and method used to identify exacerbation of multiple sclerosis (judgment of neurologist, change on a standardised neurological exam called the expanded disability status score, ${ }^{8}$ or retrospective validation by neurologist of standardised exacerbation and symptoms reported by the patient). We had intended to code for severity of disease, but markers were too variable across studies to be aggregated.

\section{Statistical analysis}

The dependent variable was occurrence of exacerbation of multiple sclerosis. The primary measure of stressful life events was the independent variable for all studies. Many of the studies report additional subanalyses of the effects of specific areas of stress (such as family, work, bereavement, etc) on exacerbation. However, there was little consistency in how these sources of stress were conceptualised or grouped, making it impossible for us to code them reliably. We therefore focused only on global stressful life events as the independent variable.

Meta-analytic calculations were conducted as described in Lipsey and Wilson, ${ }^{9}$ with the aid of their effect size calculator computer program as well as three macros written by those authors for SPSS. We calculated effect sizes from statistics provided in each article. An effect size is defined as a standardised index of the ability of stress as measured in these studies to predict clinical exacerbation of multiple sclerosis, or the magnitude of differences between the exacerbation group and the control or comparison group on the measure of stress. Weighted effect sizes were used for aggregation of effect sizes. Each effect size was weighted by the inverse variance weight, which provides an adjustment based on the sample size and standard error of the mean effect size. Once this adjustment was made we calculated $95 \%$ confidence intervals for the mean effect sizes using the simple random effects approach, which is considered a statistically conservative estimate. The effect sizes and their confidence intervals resulting from the meta-analysis are reported in Cohen's d, a standardised effect size measure $\left.\left(\left(\operatorname{mean}_{1}-\operatorname{mean}_{2}\right) / \sigma\right)\right)$. Several of the papers did not contain enough information for us to calculate Cohen's d. We therefore calculated standard errors of measurement for Fisher's z, using effect size and sample size, and translated them into Cohen's d and multiplied them by 1.96 . We used the $\mathrm{Q}$ test to test homogeneity of variance. This test examines if the observed variability in study effect sizes is within the range that can be expected if all studies shared a common population effect size. We also calculated the $I^{2}$ statistic $\left(I^{2}=100 \% *(\mathrm{Q}-\mathrm{df})\right)$, which ranges from $0-100 \%$ and provides the degree of inconsistency across studies (that is, larger percentages reflect higher degrees of inconsistency). We examined the impact of study characteristics, including sample and study design, on study effect sizes using the analog to one way analysis of variance (ANOVA) and regression. As we assumed excess variability to be due to both sampling error and random differences across studies, we fitted the data to a random effects model, which provides more conservative estimates than a fixed effects model.

\section{Results}

The literature search produced a total of 20 articles. Six papers were excluded because they did not meet inclusion criteria. ${ }^{50-14}$ The table shows the general characteristics of the 14 included studies, including sample sizes, available details of participants and the disease, study design, length of follow up, exacerbation criteria, and measurement of stress. Of the 14 studies, seven were case-control studies and seven were longitudinal prospective studies. Two studies examined first exacerbations, which led to a diagnosis of multiple sclerosis, and 12 examined exacerbations after diagnosis.

\section{Outcomes}

The figure shows the mean effect sizes and standard deviations for each study. The primary analysis for the main hypothesis found that the weighted average effect sizes for the impact of stress on exacerbation over the 14 included studies was $\mathrm{d}=0.53$ (95\% confidence interval 0.40 to 0.65$), \mathrm{P}<0.0001$. The studies' effects sizes were homogenous $(\mathrm{Q}=16.62, \mathrm{P}=0.22)$, with a low degree of inconsistency $\left(I^{2}=21.8 \%\right)$.

Effect sizes were not significantly affected by any study design characteristics, including the use of longitudinal prospective $v$ case-control designs $(\mathrm{P}=0.31)$, the use of first exacerbation $v$ exacerbation after diagnosis as an outcome criterion $(\mathrm{P}=0.59)$, the use of validated $v$ unvalidated assessment of stress $(\mathrm{P}=0.12)$, the use of self report $v$ structured interview in the assessment of stress $(\mathrm{P}=0.12)$, and the inclusion of relapsing-remitting multiple sclerosis only or relapsing-remitting multiple sclerosis and secondary-progressive multiple sclerosis $(\mathrm{P}=0.11)$. Regarding sample characteristics, neither the proportions of female participants $(\mathrm{P}=0.11)$ nor age of participants $(\mathrm{P}=0.89)$ were significantly related to effect size. None of the methods of determining exacerbation was related to outcomes, including the use of the expanded disability status score $v$ neurologist judgment $(\mathrm{P}=0.45)$, the use of expanded disability status score $\geq 1.0$, or the use of retrospective neurologist verification with standardised data $^{27}(\mathrm{P}=0.41)$.

\section{Discussion}

On the basis of this meta-analysis of 14 empirical studies, our results support the hypothesis that stress is related to exacerbation of multiple sclerosis, with a weighted average effect size of $d=0.53$. The effect sizes were statistically homogenous, indicating that these studies are comparable. Differences in study design, methods, or sample characteristics did not significantly influence the outcomes.

This effect size is clinically meaningful. As a comparison, a recent meta-analysis of the effects of interferon beta, the principal class of disease modifying drug used to treat multiple sclerosis, showed an overall effect of $d=0.36$ in reducing exacerbations in the first year and $d=0.30$ over the first two years of treatment. ${ }^{29}$ This comparison is not meant to question the use of interferon beta as the underlying biological mechanisms of interferon beta and stress are not necessarily related to each other. Rather, we suggest that the negative effects of stress on exacerbation of multiple sclerosis are at least as great as the positive effects of a class of drugs widely considered to produce clinically meaningful results.

Recent neuroimaging data have provided substantial weight to the clinical evidence on which this meta-analysis was based. The review by Goodin et al suggested that a longitudinal prospective study of stress in multiple sclerosis with gadolinium enhancing magnetic resonance imaging $(\mathrm{Gd}+\mathrm{MRI})$ as the 


\begin{tabular}{|c|c|c|c|c|c|c|c|}
\hline Study & No of participants & Mean age & Female (\%) & Design & Length of follow up & Exacerbation criterion & Stress measure \\
\hline Warren, $1982^{15}$ & $\begin{array}{l}200 \text { (100 with MS, } \\
100 \text { medical controls) }\end{array}$ & $\mathrm{N} / \mathrm{A}$ & 56.5 & Case-control & - & Neurologist confirmation & $\begin{array}{l}\text { Modification of validated } \\
\text { checklist }\end{array}$ \\
\hline$\overline{\text { Franklin, } 1988^{16}}$ & 55 with MS & 34.9 & 88.9 & Prospective & Mean 20 months & Neurologist confirmation & Validated interview \\
\hline Grant, $1989^{17}$ & $\begin{array}{l}79 \text { (39 with MS, } 40 \text { healthy } \\
\text { controls) }\end{array}$ & 35.65 & 74.4 & Case-control & - & Neurologist confirmation & Validated interview \\
\hline Warren, $1991^{18}$ & $\begin{array}{l}190 \text { with MS (95 with } \\
\text { exacerbation, } 95 \text { in } \\
\text { remission) }\end{array}$ & 35.0 & 56.5 & Case-control & - & Neurologist confirmation & Validated checklist \\
\hline Gaiatto, $1992^{19}$ & $\begin{array}{l}42 \text { with MS (20 with } \\
\text { exacerbation, } 22 \text { stable) }\end{array}$ & 49.5 & 70.0 & Case-control & - & Neurologist confirmation & Validated checklist \\
\hline$\overline{\text { Nisipeanu, } 1993^{20}}$ & 32 with MS & 38.2 & 56.3 & Prospective & 26 months & Neurologist confirmation & Single traumatic event \\
\hline Stip, $1994^{21}$ & $\begin{array}{l}68 \text { (35 with MS, } 33 \text { medical } \\
\text { controls) }\end{array}$ & 42.5 & 60.0 & Case-control & - & Neurologist confirmation & Validated checklist \\
\hline Morrison, $1994^{212}$ & 17 with MS & 73.4 & 73.4 & Prospective & Mean 24 months & 0.5 increase on EDSS & $\begin{array}{l}\text { Modification of validated } \\
\text { checklist }\end{array}$ \\
\hline Gasperini, $1995^{23}$ & $\begin{array}{l}178 \text { with MS (89 with } \\
\text { exacerbation, } 89 \text { stable } \\
\text { controls) }\end{array}$ & 35.6 & 69.7 & Case-control & - & 1.0 increase on EDSS & Unvalidated questionnaire \\
\hline Sibley, $1997^{24}$ & $\begin{array}{l}304 \text { (170 with MS, } \\
134 \text { healthy controls) }\end{array}$ & 41.5 & 62.5 & Prospective & Mean 5.2 years & Neurologist confirmation & Unvalidated interview \\
\hline Palumbo, $1998^{25}$ & $\begin{array}{l}92 \text { ( } 65 \text { with MS, } 27 \text { medical } \\
\text { control) }\end{array}$ & 45.0 & 61.5 & Case-control & - & Neurologist confirmation & Unvalidated questionnaire \\
\hline$\overline{\text { Mohr, } 2000^{26}}$ & 36 with MS & 44.0 & 61.1 & Prospective & Mean 10 months & 1.0 increase on EDSS & $\begin{array}{l}\text { Modification of validated } \\
\text { checklist }\end{array}$ \\
\hline Ackerman, $2003^{27}$ & 50 with MS & 39.4 & 100 & Prospective & 12 months & $\begin{array}{l}\text { Patient report and } \\
\text { retrospective neurologist } \\
\text { confirmation }\end{array}$ & Validated/interview \\
\hline Buljevac, $2003^{28}$ & 73 with RRMS & 39.9 & 76.7 & Prospective & Mean 17 months & Neurologist confirmation & Weekly diary \\
\hline
\end{tabular}

EDDS= expanded disability status score; $N / A=$ not available; RRMS= relapsing-remitting multiple sclerosis.

primary outcome would "convincingly test the relationship." $\mathrm{Gd}+\mathrm{MRI}$ can detect breakdown in the blood-brain barrier and is therefore a highly sensitive marker of lesion formation in multiple sclerosis and is highly predictive of subsequent clinical exacerbation. Subsequent to the Goodin et al review, a prospective study of 36 patients with multiple sclerosis receiving monthly gadolinium enhancing magnetic resonance imaging showed that the occurrence of interpersonal stressors was associated with a significantly increased risk of a new brain lesion eight weeks later. ${ }^{25}$

Our meta-analysis is an improvement over the previous qualitative review, which included a study by Rabins et al. ${ }^{5}$ We did not include this because the data and statistics provided were not suffi-

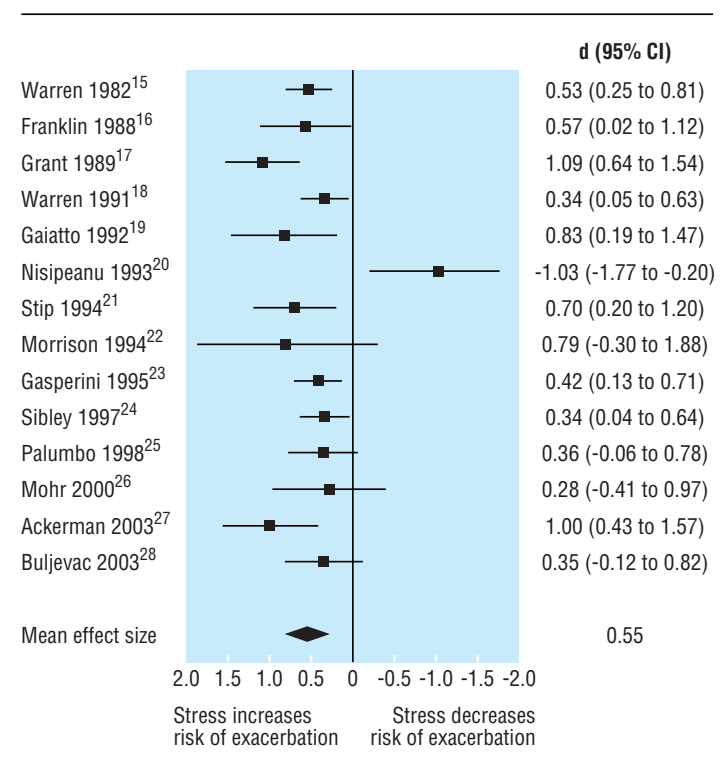

Effect of stress on exacerbations in multiple sclerosis cient to calculate an effect size. Our meta-analysis also contained seven studies that the Goodin et al review omitted. ${ }^{12122} 24-26$

\section{Is all stress the same?}

While our findings were statistically homogenous, the study by Nisipeanu and Korczyn, in contrast to all other published reports, found that stress reduced the risk of exacerbation. ${ }^{19}$ These findings raise the important hypothesis that different types of stressors may have different effects. While all other studies examined normal everyday stress, Nisipeanu and Korczyn examined the effects of a traumatic, life threatening stressornamely, being under one month of missile attacks in Tel Aviv during the first Gulf war. The finding that traumatic stressors reduced the risk of exacerbations is consistent with animal models and other biological data. Numerous studies of stress in experimental autoimmune encephalomyelitis, an animal model of multiple sclerosis, have shown significant reductions in symptoms related to stress. ${ }^{30}$ Stress is known to increase the release of cortisol, and cortisol is known to be a potent anti-inflammatory hormone. ${ }^{31}$ However, more moderate stressors have been shown to activate experimental autoimmune encephalomyelitis. ${ }^{32}$

\section{Potential mechanisms}

At least one study has found that reducing distress in people with multiple sclerosis can reduce T cell production of $\gamma$ interferon, ${ }^{33}$ a proinflammatory cytokine believed to be vital in the pathogenesis of exacerbation. ${ }^{2}$ However, no biological mechanism linking stress or distress and inflammatory processes in multiple sclerosis has been tested. Animal studies have suggested several potential mechanisms. Small increases of cortisol concentrations, similar to concentrations seen in non-traumatic stress, have been shown to enhance the sensitivity of T cells to a number of cytokines and peptides that promote a proinflammatory response. ${ }^{34}$ Alternatively, sustained increases in cortisol concentration in response to chronic stress produce a counter-regulatory reduction in the number, binding capacity, and affinity of gluco- 
corticoid receptors on immune cells, ${ }^{35}$ increasing risk of inflammation. Finally, mast cells, which reside in the endothelium, can be activated by increases in corticotropin releasing factor related to stress. Activated mast cells increase the permeability of the blood-brain barrier and increase inflammation through the release of tumour necrosis factor $\alpha$, histamines, and tryptase. ${ }^{36}$ While these potential mechanisms are intriguing, none has been adequately tested among patients with multiple sclerosis. The absence of a clear biological model is a substantial weakness in the current literature.

\section{Limitations and recommendations}

Our meta-analysis had several limitations. The quality of the studies included varied. Even the best longitudinal prospective designs, which permit stronger inferences than case-control studies, do not offer absolute evidence of a causal association. Other unmeasured factors may affect both the perception of stress and exacerbation. For example, changes in normal appearing white matter may occur months before traditional neuroimaging markers of inflammation or clinical exacerbation. ${ }^{37}$ Thus, we cannot rule out the hypothesis that decreased ability to manage stressors or increased perceived stress may be an early marker of changes in normal appearing white matter.

On the basis of our review, we can recommend issues for future research. Because distress resulting from stressful life events can increase the perceived severity of symptoms, objective measures of exacerbation or inflammation are critical. To examine the potential differential effects of various types of stressors, various dimensions of stressful life events must be carefully assessed, including severity, chronicity, type, and source. Variability in individual reactions to stressful events, including cognitive appraisal and subjective distress, will help to tease apart the effects of environment and individual psychological differences. The development and evaluation of potential biological pathways has received little attention. Finally, the association between stress and exacerbation in multiple sclerosis can be conclusively confirmed only with a clinical trial of a behavioural intervention that teaches patients to reduce the occurrence and impact of stress.

In summary, it is important to note that while these findings show a significant association between stress and exacerbation in multiple sclerosis, the effect size is modest. This association is not consistent across patients or even within individual patients across time. The potential differential effects of various types of stress or the mechanisms by which stress affects inflammation are not known. Thus, the occurrence of any specific exacerbation cannot yet be linked to any specific stressor. Furthermore, these findings should in no way be misconstrued to suggest that patients with multiple sclerosis bear any responsibility for exacerbations. Rather, we hope that these findings will open investigation into new avenues of managing multiple sclerosis, either through stress management or through pharmacological management of potential neuroendocrine or immune responses to stress.

We thank Irina Fonareva for assisting in the preparation of the manuscript and presentation of the data.

Contributors: DCM initially conceived the paper and is guarantor. All authors participated in data acquisition, analysis, and writing.

Funding: US National Institutes of Health grants R01 MH59708-01 and R01 HD043323-01 and National Multiple Sclerosis Society grants FG 1481-A1 and FG 1376A1.

Competing interests: None declared.

Ethical approval: Not required.

1 Noseworthy JH, Lucchinetti C, Rodriguez M, Weinshenker BG. Multiple sclerosis. N Engl J Med 2000;343:938-52.
What is already known on this topic

Most patients with multiple sclerosis believe that stressful life events can cause exacerbations of their illness

The potential role of stressful life events on exacerbation remains controversial among care providers and academics

What this study adds

Non-traumatic stressful life events are associated with an increased risk of exacerbation in patients with multiple sclerosis

The association between stressful life events and exacerbation is complex and cannot currently be determined for any individual patient

2 Hohlfeld R, Meinl E, Weber F, Zipp F, Schmidt S, Sotgiu S, et al. The role of autoimmune $\mathrm{T}$ lymphocytes in the pathogenesis of multiple sclerosis. Neurology 1995;45(6 suppl 6):S33-8

3 Goodin DS, Ebers GC, Johnson KP, Rodriguez M, Sibley WA, Wolinsky JS. The relationship of MS to physical trauma and psychological stress: report of the therapeutics and technology assessment subcommittee of the American Academy of Neurology. Neurology 1999;52:1737-45.

4 Charcot JM. Lectures on diseases of the nervous system. London: New Sydenham Society, 1877 .

Rabins PV, Brooks BR, O’Donnell P, Pearlson GD, Moberg P, Jubelt B, et al. Structural brain correlates of emotional disorder in multiple sclerosis. Brain 1986;109:585-97.

6 Schumacher GA, Beebe G, Kibler RF, Durland LT, Kurtzke JF, McDowell F, et al. Problems of experimental trials of therapy in multiple sclerosis. Report by the panel on the lems of experimental trials of therapy in multiple sclerosis. Report by the panel on the
evaluation of experimental trials of therapy in multiple sclerosis. Ann N Y Acad Sci evaluation of exper.

7 Poser CM, Paty DW, Scheinberg L, McDonald WI, Davis FA, Ebers GC, et al. New diagnostic criteria for multiple sclerosis: guidelines for research protocols. Ann Neurol 1983;13:227-31.

8 Kurtzke JF. Rating neurologic impairment in multiple sclerosis: an expanded disability status scale (EDSS). Neurology 1983;33:1444-52],

9 Lipsey MW, Wilson DB. Practical meta-analysis. Thousand Oaks, CA: Sage, 2001.

10 Pratt RTC. An investigation of the psychiatric aspects of disseminated sclerosis. J Neurol Neurosurg Psychiatry 1951;14:326-36.

11 Antonovsky A, Leibowitz U, Medalie JM, Smith A, Halpern L, Alter M. Reappraisal of possible etiologic factors in multiple sclerosis. Am J Public Health 1968;58:836-48.

12 Mei-Tal V, Meyerowitz S, Engel GL. The role of psychological process in a somatic disMei-Tal V, Meyerowitz S, Engel GL. The role of psychological process in a somatic dis-
order: multiple sclerosis. 1. The emotional setting of illness onset and exacerbation. order: multiple sclerosis. 1. The
Psychosom Med 1970;32:67-86.

13 Schwartz CE, Foley FW, Rao SM, Bernardin LJ, Lee H, Genderson MW. Stress and course of disease in multiple sclerosis. Behav Med 1999;25:110-6.

14 Ackerman KD, Rabin B, Heyman R, Frank E, Anderson B, Baum A. Stressful life events precede multiple sclerosis disease exacerbations. Psychosom Med 2000;62:147.

15 Warren S, Greenhill S, Warren KG. Emotional stress and the development of multiple sclerosis: case-control evidence of a relationship. J Chronic Dis 1982;35:821-31.

16 Franklin GM, Nelson LM, Heaton RK, Burks JS, Thompson DS. Stress and its relationship to acute exacerbations in multiple sclerosis. J Neurol Rehabil 1988;2:7-11.

17 Grant I, Brown GW, Harris T, McDonald WI, Patterson T, Trimble MR. Severely threatGrant I, Brown GW, Harris T, McDonald WI, Patterson T, Trimble MR. Severely threat-
ening events and marked life difficulties preceding onset or exacerbation of multiple ening events and marked life difficulties preceding
sclerosis. J Neurol Neurosurg Psychiatry 1989;52:8-13.

18 Warren S, Warren KG, Cockerill R. Emotional stress and coping in multiple sclerosis (MS) exacerbations. J Psychosom Res 1991;35:37-47.

19 Gaiatto G, Loperfido A, Fortunaso P. Eventi stressanti e ricadute nella sclerosi multipla; Uno studio pilota [Stressful events and exacerbations in multiple sclerosis: A pilot study]. Medicina Psicosomatica 1992;37:19-27.

20 Nisipeanu P, Korczyn AD. Psychological stress as risk factor for exacerbations in multiple sclerosis. Neurology 1993;43:1311-2.

21 Stip E, Truelle JL. [Organic personality syndrome in multiple sclerosis and effect of stress on recurrent attacks]. Can J Psychiatry 1994;39:27-33.

22 Morrison W, Nelson J. Environmental triggers in multiple sclerosis. Fact or fallacy? Axone 1994;16:23-6.

23 Gasperini C, Grasso MG, Fiorelli M, Millefiorini E, Morino S, Anzini A, et al. A controlled study of potential risk factors preceding exacerbation in multiple sclerosis. J Neurol Neurosurg Psychiatry 1995;59:303-5.

24 Sibley WA. Risk factors in multiple sclerosis. In: Raine CS, McFarland HF, Tourtellotte WW, eds. Multiple sclerosis: clinical and pathogenetic basis. London: Chapman and Hall, 1997:141-8.

25 Palumbo R, Fontanillas L, Salmaggi A, La Mantia L, Milanese C. Stressful life events and multiple sclerosis: a retrospective study. Ital J Neurol Sci 1998;19:259-60.

26 Mohr DC, Goodkin DE, Bacchetti P, Boudewyn AC, Huang L, Marrietta P, et al. Psychological stress and the subsequent appearance of new brain MRI lesions in MS. Neurology 2000;55:55-61.

27 Ackerman KD, Stover A, Heyman R, Anderson BP, Houck PR, Frank E, et al. Relationship between cardiovascular reactivity, stressful life events, and multiple sclerosis ship between cardiovascular reactivity, stressful life
disease activity. Brain Behavior Immun 2003;17:141-51.

28 Buljevac D, Hop WC, Reedeker W, Janssens AC, van der Meche FG, van Doorn PA, et al. Self reported stressful life events and exacerbations in multiple sclerosis: prospective study. BMJ 2003;327:646. 
29 Filippini G, Munari L, Incorvaia B, Ebers GC, Polman C, D'Amico R, et al. Interferons in relapsing remitting multiple sclerosis: a systematic review. Lancet 2003;361:545-52.

30 Whitacre CC, Dowdell K, Griffin AC. Neuroendocrine influences on experimental autoimmune encephalomyelitis. Ann N Y Acad Sci 1998;840:705-16.

31 Chrousos GP. The hypothalamic-pituitary-adrenal axis and immune-mediated inflammation. N Engl J Med 1995;332:1351-62.

32 Correa SG, Rodriguez-Galâan MC, Rivero VE, Riera CM. Chronic varied stress modulates experimental autoimmune encephalomyelitis in Wistar rats. Brain Behav Immunity 1998;12:134-48.

33 Mohr DC, Goodkin DE, Islar J, Hauser SL, Genain CP. Treatment of depression is associated with suppression of nonspecific and antigen-specific $\mathrm{T}(\mathrm{H}) 1$ responses in multiple sclerosis. Arch Neurol 2001;58:1081-6.

34 Munck A, Naray-Fejes-Toth A. Glucocorticoids and stress: permissive and suppressive actions. Ann N Y Acad Sci 1994;746:115-30,131-3.

35 Kino T, Chrousos GP. Glucocorticoid and mineralocorticoid resistance/ hypersensitivity syndromes. J Endocrinol 2001;169:437-45.

36 Zappulla JP, Arock M, Mars LT, Liblau RS. Mast cells: new targets for multiple sclerosis therapy? J Neuroimmunol 2002;131:5-20.

37 Goodkin DE, Rooney WD, Sloan R, Bacchetti P, Gee L, Vermathen M, et al. A serial study of new MS lesions and the white matter from which they arise. Neurology 1998;51:1689-97.

(Accepted 22 January 2004)

doi $10.1136 /$ bmj.38041.724421.55
Department of Psychiatry, University of California, San Francisco, CA 94142, USA David C Mohr associate professor

Stacey L Hart assistant professor

Department of Medicine, University of California, San Francisco

Laura Julian postdoctoral fellow

Department of Neurology, University of California, San Francisco

Darcy Cox assistant professor

Daniel Pelletier assistant professor

Correspondence to: D Mohr dmohr@itsa.ucsf.edu

\section{Amendment}

This is Version 2 of the paper. In this version, there has been a change in the table to the entry for Gasperini under the heading "Stress measure." Where it read "1.0 increase in EDSS" this has been corrected to read "Unvalidated questionnaire." 